\title{
Corrosion Behaviors of Sputtered NiTiCu Shape Memory Films
}

\author{
Nan Ye ${ }^{(1)}$, Xueping Ren* \\ School of Materials Science and Engineering, University of Science and Technology Beijing, Beijing, China \\ Email: *rxp33@ustb.edu.cn
}

How to cite this paper: Ye, N. and Ren, X.P. (2020) Corrosion Behaviors of Sputtered NiTiCu Shape Memory Films. Journal of Materials Science and Chemical Engineering, 8, 7-15.

https://doi.org/10.4236/msce.2020.82002

Received: September 17, 2019

Accepted: January 17, 2020

Published: January 20, 2020

Copyright $\odot 2020$ by author(s) and Scientific Research Publishing Inc. This work is licensed under the Creative Commons Attribution International License (CC BY 4.0).

http://creativecommons.org/licenses/by/4.0/

\section{(c) (i) Open Access}

\begin{abstract}
For $\mathrm{NiTiCu} \mathrm{SMA}$, the $\mathrm{Ni}$ atoms are substituted by $\mathrm{Cu}$ atoms, which not only greatly reduce the alloy cost, but also have excellent shape memory effect. Four kinds of shape memory alloy films $\left(\mathrm{Ni}_{49.6} \mathrm{Ti}_{50.4}, \mathrm{Ni}_{48.2} \mathrm{Ti}_{50.4} \mathrm{Cu}_{1.4}\right.$, $\left.\mathrm{Ni}_{45.6} \mathrm{Ti}_{50.4} \mathrm{Cu}_{4}, \mathrm{Ni}_{42.7} \mathrm{Ti}_{50.4} \mathrm{Cu}_{6.9}\right)$ were prepared using magnetron sputtering. Corrosion behaviors of the four films in phosphate buffered saline (PBS) solutions at $37^{\circ} \mathrm{C}$ were examined using electrochemical impedance spectroscopy (EIS) method. It was found that the corrosion resistance of the NiTi film is superior to the three NiTiCu films. The EIS data were fitted using a parallel resistance-capacitance (as a constant phase element) circuit associated with the surface oxide film. The thickness of the surface oxide layer of the three $\mathrm{NiTiCu}$ films increases with applied potential till $0.8 \mathrm{~V}$, while that of the NiTi film can reach to $1.2 \mathrm{~V}$.
\end{abstract}

\section{Keywords}

Corrosion, NiTiCu Shape Memory Alloy, Electrochemical Impedance Spectroscopy, NiTiCu Films

\section{Introduction}

Shape memory alloys (SMA) have attracted much attention over the past few decades, and NiTi SMA is one of the most studied among other SMAs [1] [2] [3] [4] [5]. As a typical shape memory alloy, NiTi alloys have been widely used in many applications such as industry, medicine, aerospace and construction. In recent years, NiTi films are extensively studied. It has been reported that the properties of NiTi films are similar to those of bulk NiTi SMAs. NiTi films have been tried to be applied to biomedical devices. Magnetron sputtering deposition is considered to be one of the suitable methods to process NiTi films. When NiTi films are deposited at ambient temperatures, they are usually amorphous, and 
the shape memory and superelasticity can be introduced by crystallization.

The main application of binary NiTi SMAs is in the field of biomedical devices. For biomedical applications, nickel-titanium SMAs can be used to manufacture esophageal, tracheal, vascular, biliary, urethral and other stents and orthopedic internal fixation devices such as embracing fixators, bone clasps, intramedullary nails, etc. [6] [7] [8]. For NiTiCu SMA, the Ni atoms are substituted by $\mathrm{Cu}$ atoms, which not only greatly reduce the alloy cost, but also greatly reduce the transformation temperature sensitivity to the Ti:Ni ratio, and the transformation hysteresis is greatly reduced. However, the shape memory effect is still excellent [9]. Therefore, NiTiCu SMAs have attracted some attention from both industrial applications and academic researches [10] [11] [12]. According to the study of localized corrosion of NiTiCu alloy in different conditions at a temperature of $40^{\circ} \mathrm{C}$ and a concentration of $0.9 \% \mathrm{NaCl}$ solution, it has found that $\mathrm{Ni}$ $\mathrm{TiCu}$ has a significantly lower corrosion potential than that of the NiMo binary alloy. However, the difference in the percentage of $\mathrm{Cu}$ atoms and the change in phase transition state will have a certain effect on the alloy [13]. The research on $\mathrm{Ti}_{50} \mathrm{Ni}_{40} \mathrm{Cu}_{10}$ SMA shows that, the addition of $\mathrm{Cu}$ element makes the corrosion resistance of the alloy in Hank's solution significantly reduced. Moreover, the experimental results of further cytotoxicity of the alloy show that the $\mathrm{Ti}_{50} \mathrm{Ni}_{40} \mathrm{Cu}_{10}$ shape memory alloy has higher cytotoxicity than the binary NiTi and $\mathrm{Ti}$ alloys [14]. In a word, the safety of applying NiTiCu shape memory alloys needs further exploration.

The application range of electrochemical impedance spectroscopy (EIS) includes: corrosion and protection of metals, metal/polymer composites, semiconductor materials; polycrystalline solids, and ceramic materials. Many studies have used EIS to detect corrosion behavior of titanium alloys [15] [16] [17]. However, there are few reports on the corrosion behavior of sputtered $\mathrm{NiTiCu}$ shape memory alloys in simulated physiological solution. Therefore, this work used the EIS method to study the corrosion behavior of NiTiCu shape memory alloys with different $\mathrm{Cu}$ contents.

\section{Experiment Procedures}

Four kinds of SMAs $\left(\mathrm{Ni}_{49.6} \mathrm{Ti}_{50.4}, \mathrm{Ni}_{48.2} \mathrm{Ti}_{50.4} \mathrm{Cu}_{1.4}, \mathrm{Ni}_{45.6} \mathrm{Ti}_{50.4} \mathrm{Cu}_{4}, \mathrm{Ni}_{42.7} \mathrm{Ti}_{50.4} \mathrm{Cu}_{6.9}\right)$ were magnetron sputtered on Si substrates. Films were co-sputtered $\mathrm{NiTiCu}$ and $\mathrm{Ti}$ (at $400 \mathrm{~W}$ and $70 \mathrm{~W}$ DC plasma power) targets at ambient temperature. The target diameter was $100 \mathrm{~mm}$, and the substrate was $\mathrm{Si}_{3} \mathrm{~N}_{\mathrm{x}}$ coated silicon wafer. The base vacuum was $2.0 \times 10^{-7}$ Torr, and the argon pressure was $2.4 \mathrm{mTorr}$. The final film thickness is around $1 \mu \mathrm{m}$. The films were all amorphous, and subsequent crystallization is a must to introduce the shape memory effect. The crystallization was conducted in high vacuum (basic vacuum of $5 \times 10^{-6} \mathrm{Torr}$ ) at a temperature of $650^{\circ} \mathrm{C}$.

The EIS test based on the films was conducted from the potential $\mathrm{E}_{\text {corr }}$ to $1.2 \mathrm{~V}$ (a saturated calomel electrode, SCE) in a step of $0.2 \mathrm{~V}$ at a DC potential. After 
immersing the sample in PBS solution at $37^{\circ} \mathrm{C}, \mathrm{E}_{\text {corr }}$ was monitored for $60 \mathrm{mi}$ nutes. When the potential was gradually increased to a subsequent value, the current was allowed to stabilize for 15 minutes before the measurement.

\section{Result and Discussion}

The surface oxide layer of the NiTi film was characterized using EIS, and Figure 1 (a) is the complex Nyquist plot. The impedance decreases as the potential increasing from 0 to $1.2 \mathrm{~V}$. When the potential is increased from $0.2 \mathrm{~V}$ to $0.4 \mathrm{~V}$, the impedance shows a large decrement at low frequencies. As the potential is further increased to $1.0 \mathrm{~V}$, the amount of impedance decrement decreases. When the potential increases to $1.2 \mathrm{~V}$, the impedance decreases significantly and forms a semicircular shape. This behavior is attributed to the oxidation of the solution, not the breakdown of the oxide layer on the surface of the film [16] [18].

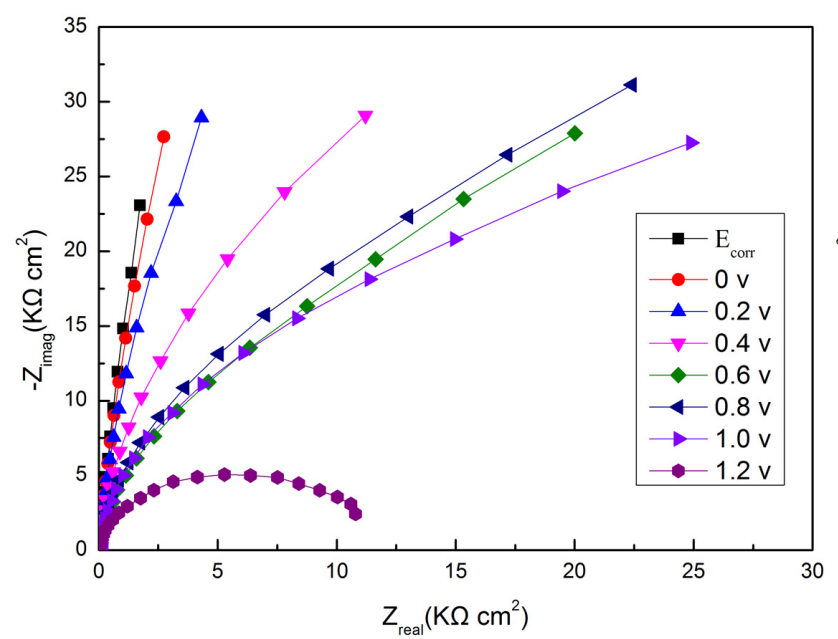

(a)

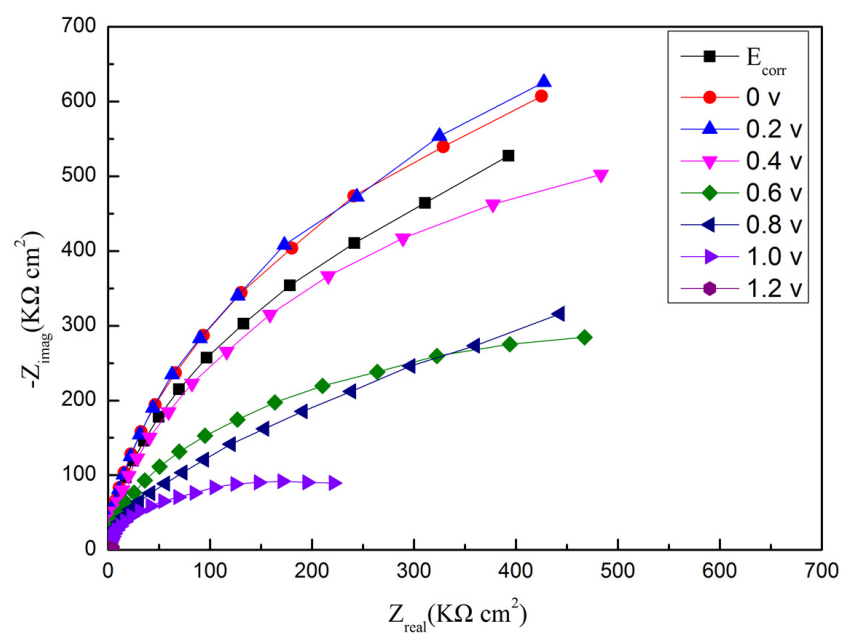

(c)

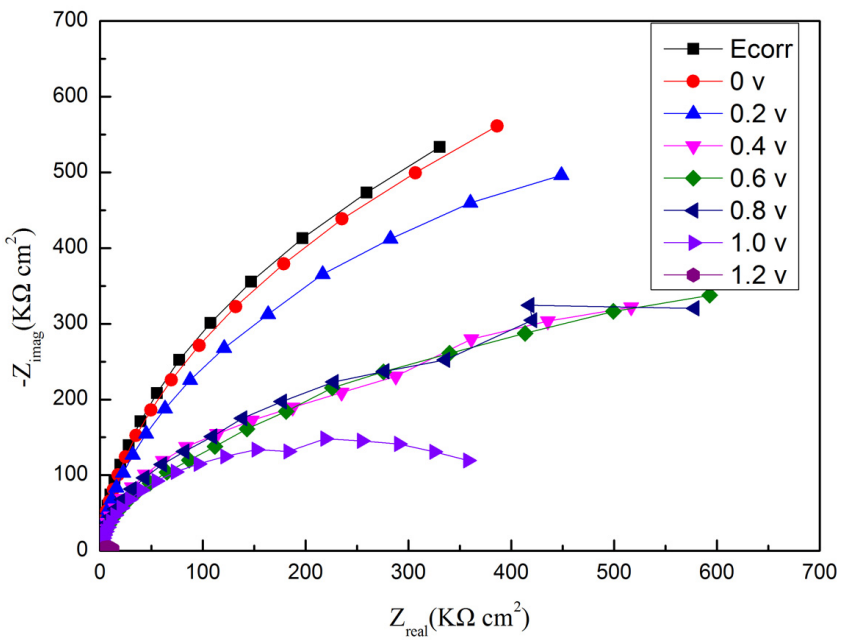

(b)

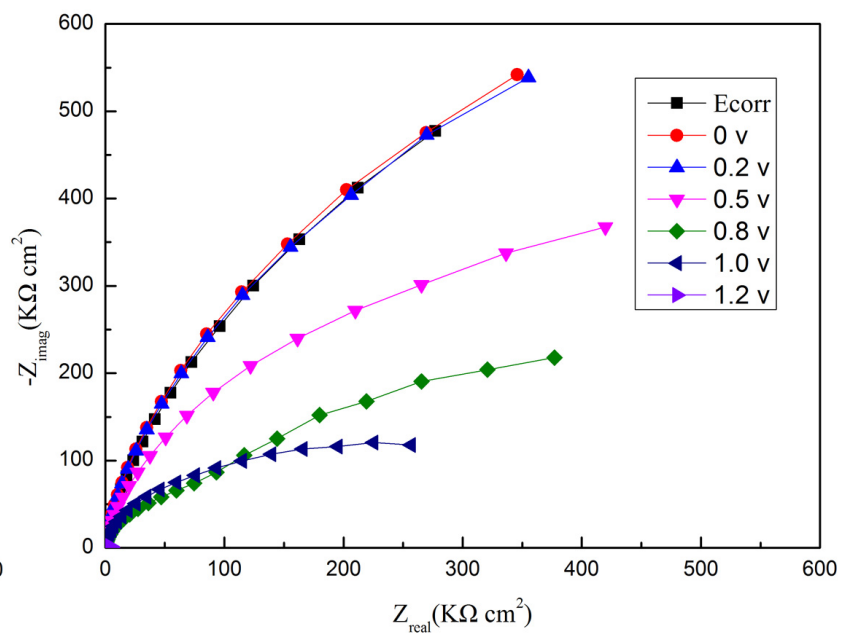

(d)

Figure 1. The Nyquist plots of the four films in PBS solution at $37^{\circ} \mathrm{C}$ ((a) $\mathrm{Ni}_{49.6} \mathrm{Ti}_{50.4} ;$ (b) $\mathrm{Ni}_{48.2} \mathrm{Ti}_{50.4} \mathrm{Cu}_{1.4} ;(\mathrm{c}) \mathrm{Ni}_{45.6} \mathrm{Ti}_{50.4} \mathrm{Cu}_{4} ;(\mathrm{d})$ $\left.\mathrm{Ni}_{42.7} \mathrm{Ti}_{50.4} \mathrm{Cu}_{6.9}\right)$. 
The Nyquist polt of the $\mathrm{Ni}_{48.2} \mathrm{Ti}_{50.4} \mathrm{Cu}_{1.4}$ film is shown in Figure 1(b). With the potential increasing, the impedance decay behavior is similar as that of the NiTi film. When the potential is increased from $0.2 \mathrm{~V}$ to $0.4 \mathrm{~V}$, the impedance decreases significantly. As the potential is further increased to $0.8 \mathrm{~V}$, the amount of impedance decrement decreases. When the potential is increased to $1.0 \mathrm{~V}$, the impedance shows a significant attenuation, and appears semicircular as the potential rises to $1.2 \mathrm{~V}$. The Nyquist plot of the $\mathrm{Ni}_{45.6} \mathrm{Ti}_{50.4} \mathrm{Cu}_{4}$ film is as shown in Figure $1(\mathrm{c})$, and its variation is similar to that of the $\mathrm{Ni}_{48.2} \mathrm{Ti}_{50.4} \mathrm{Cu}_{1.4}$ film. When the potential is increased from $0.4 \mathrm{~V}$ to $0.6 \mathrm{~V}$, the impedance decreased largely. The Nyquist plot of a $\mathrm{Ni}_{45.6} \mathrm{Ti}_{50.4} \mathrm{Cu}_{4}$ film is shown in Figure $1(\mathrm{~d})$, and its variation is similar to those of the other two NiTiCu films. When the potential is increased from $0.2 \mathrm{~V}$ to $0.5 \mathrm{~V}$, the impedance decreases significantly.

Figures 2(a)-(d) is the Bode plot of the four films. The effect of the potential is more pronounced in the phase shift angle. For the NiTi film, when the potential was increased to $1.2 \mathrm{~V}$, the phase shift angle $(\theta)$ was close to $90^{\circ}$ in a certain frequency range, showing near-capacitive behavior. The impedance $|Z|$ varies linearly within this range with a slope of -1 . However, when the potential was

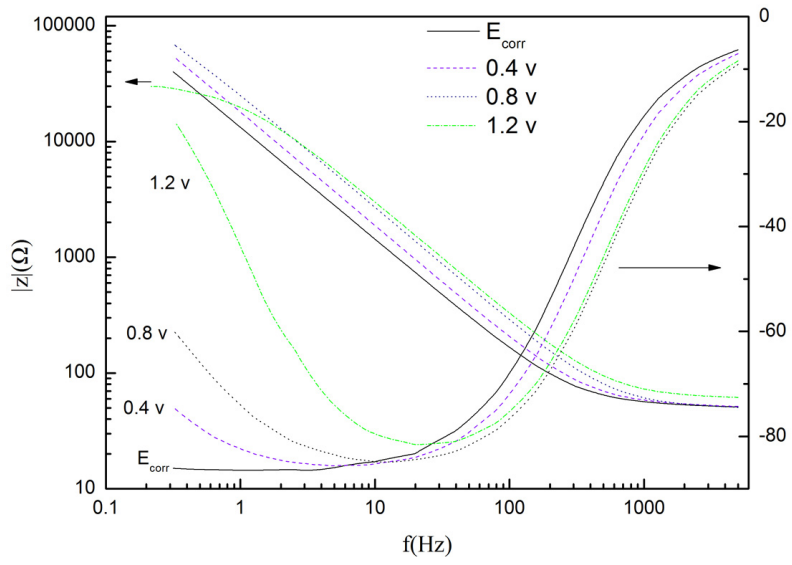

(a)

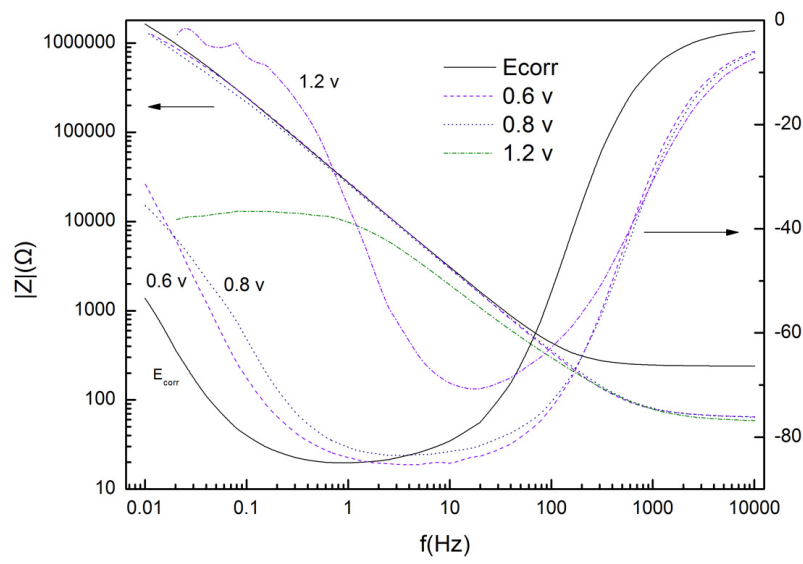

(c)

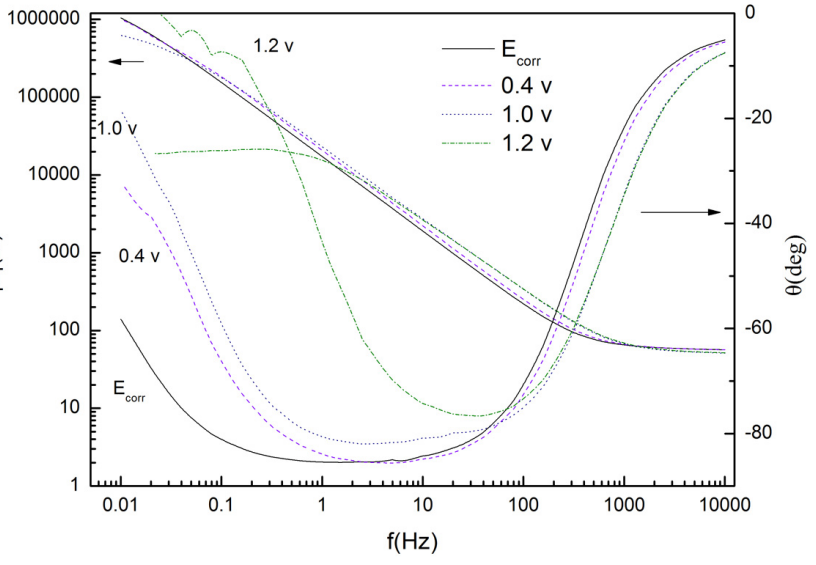

(b)

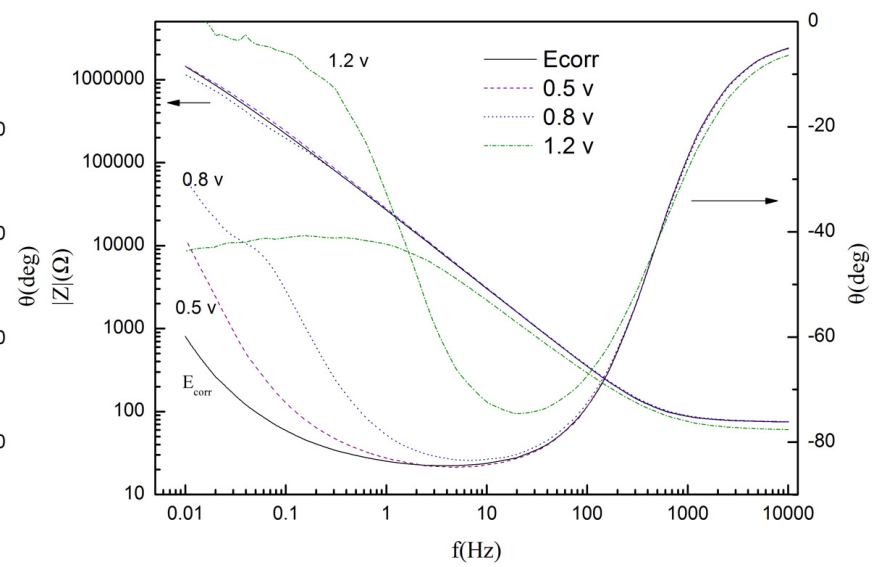

(d)

Figure 2. The Bode plots of four films in PBS solution at $37^{\circ} \mathrm{C}$ ((a) $\mathrm{Ni}_{49.6} \mathrm{Ti}_{50.4} ;$ (b) $\mathrm{Ni}_{48.2} \mathrm{Ti}_{50.4} \mathrm{Cu}_{1.4} ;$ (c) $\mathrm{Ni}_{45.6} \mathrm{Ti}_{50.4} \mathrm{Cu}_{4} ;(\mathrm{d})$ $\left.\mathrm{Ni}_{42.7} \mathrm{Ti}_{50.4} \mathrm{Cu}_{6.9}\right)$. 
increased to $1.2 \mathrm{~V}$, the maximum phase shift angles of the $\mathrm{Ni}_{48.2} \mathrm{Ti}_{50.4} \mathrm{Cu}_{1.4}$ film, the $\mathrm{Ni}_{48.2} \mathrm{Ti}_{50.4} \mathrm{Cu}_{1.4}$ film, and the $\mathrm{Ni}_{42.7} \mathrm{Ti}_{50.4} \mathrm{Cu}_{6.9}$ film were $76^{\circ}, 70^{\circ}$, and $74^{\circ}$, respectively. It is implying that the near-capacitance behavior of the surfaces of these three films is broken. When the potential was $1.2 \mathrm{~V}$, the maximum phase shfit angle of the NiTi film is much larger than that of the other three NiTiCu films, indicating that the corrosion resistance of the NiTi film is superior to that of the other three NiTiCu films [16] [18].

At a potential of 1.2 V, the Bode plots of the four films are shown in Figure 3. The impedance difference of the four films is more clearly shown in Figure 3. The NiTi film has a higher impedance $|Z|$ value than the other three $\mathrm{NiTiCu}$ films, and its maximum phase shift angle $\theta$ is much larger than the other three NiTiCu films. It implies that the corrosion resistance of NiTi film is better than the other three NiTiCu films.

The near-capacitive behavior of the film in solution allows a simple equivalent circuit to represent the impedance component of the films. In the literature, there are also reports on the use of equivalent circuits to simulate impedance. $\mathrm{K}$ Li et al. used a similar equivalent circuit when studying the impedance of NiTi film in PBS solution [18]. Popa used a parallel circuit of $R_{o x}$ and $C_{o x}$ to represent the impedance of Ti in Ringer's solution [19]. Pound also used the same method when studying the impedance of Nitinol in PBS and simulated bile solutions [16]. The Bode plots showed that the impedance of NiTi and NiTiCu in PBS can be represented by the simple equivalent circuit shown in Figure 4 . The circuit consists of an ohmic resistor $\left(R_{s o l}\right)$ of the solution, a resistance of the passivation oxide film $\left(R_{o x}\right)$ and a constant phase element (CPE) associated with the oxide. The formula associated with CPE is as follows:

$$
Z_{C P E}=\left[\frac{1}{Y_{0}(j \omega)^{\alpha}}\right]
$$

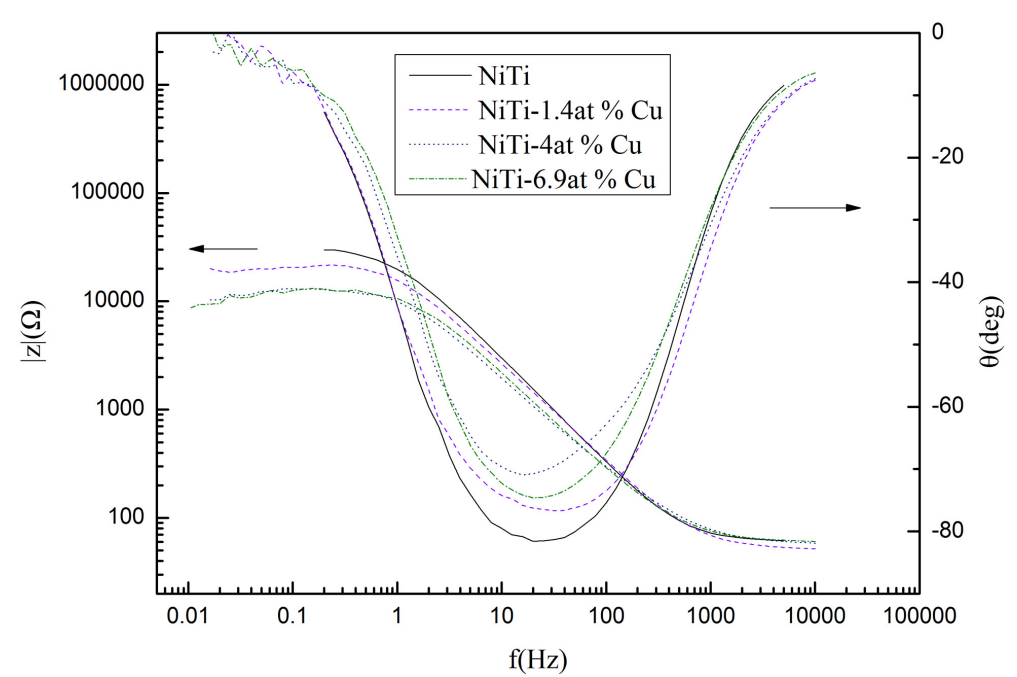

Figure 3. The Bode plots of four films in PBS solution at $37^{\circ} \mathrm{C}$ (potential is 1.2 $\mathrm{V})$. 


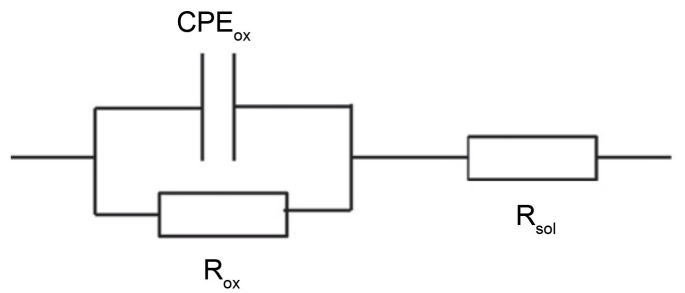

Figure 4. RC equivalent circuit in PBS solution.

where $Y_{0}$ is the constant phase element parameter, $j=\sqrt{-1}, \omega$ is the angular frequency $R_{s o p}$ and the values of $R_{o x}, Y_{0}$ and $\alpha$ can be obtained using a nonlinear least squares curve fitting program. The $\alpha$ value of the amorphous NiTi film was found to be between 0.94 and 0.97 . Since $\alpha$ is close to $1, Y_{0}$ can be taken as the value of $C_{o x}$ [13] [15].

The thickness $d_{o x}$ of the film surface oxide can be calculated by the value of $C_{o x}$ and the calculation formula is as the following,

$$
d_{o x}=\frac{\varepsilon \varepsilon_{0}}{C_{o x}}
$$

where $\varepsilon$ is the dielectric constant of the surface oxide, $\varepsilon_{0}$ is the permittivity of the free space $\left(8.854 \times 10^{-12} \mathrm{Fm}^{-1}\right)$, and the surface oxide of the NiTi film is mainly $\mathrm{TiO}_{2}$. In the current study, the dielectric constant is 100 [18].

The calculation results of the thickness of surface oxide layer are shown in Figure 5. The thickness of oxide layer on the surface of several thin film materials were continually increasing in PBS solution as the potential increased. The thickness of the oxide layer of the NiTi film is calculated about $8 \mathrm{~nm}$ at $\mathrm{E}_{\text {corr }}$, which is smaller than the other three NiTiCu films. For the $\mathrm{Ni}_{48.2} \mathrm{Ti}_{50.4} \mathrm{Cu}_{1.4}$ film, the thickness of the surface oxide does not change much when the potential reaches $0.8 \mathrm{~V}$. However, for $\mathrm{Ni}_{45.6} \mathrm{Ti}_{50.4} \mathrm{Cu}_{4}$ film and $\mathrm{Ni}_{42.7} \mathrm{Ti}_{50.4} \mathrm{Cu}_{6.9}$ films, the oxide thickness decreases with further increasing potential above $0.8 \mathrm{~V}$. The oxide thickness of the $\mathrm{Ni}_{49.6} \mathrm{Ti}_{50.4}$ film is increased until the voltage reaches $1.2 \mathrm{~V}$. It is generally believed that when the applied voltage is above $0.8 \mathrm{~V}$, oxygen evolution will begin, which will affect the corrosion behavior of the test sample. Even if the voltage is above $0.8 \mathrm{~V}$, the oxide thickness of the $\mathrm{Ni}_{49.6} \mathrm{Ti}_{50.4}$ film still continuously increases, which means that the NiTi film has better anti-oxidized capability than the other three NiTiCu films. In addition, the oxide film thickness of $\mathrm{Ni}_{48.2} \mathrm{Ti}_{50.4} \mathrm{Cu}_{1.4}$ film has no significant decrement when the voltage reached $0.8 \mathrm{~V}$, indicating that its anti-oxidized capability is better than the other two $\mathrm{Cu}$-containing films.

Based on the assumption that the oxide resistance is a linear function of the thickness of the oxide layer, the resistivity $\left(\rho_{o x}\right)$ of the oxide layer of the thin film $s$ obtained from the thickness of the oxide layer as following,

$$
\rho_{o x}=\frac{R_{o x}}{d_{o x}}
$$

where $d_{o x}$ is the thickness of the oxide layer and $R_{o x}$ is the resistance of the oxide 


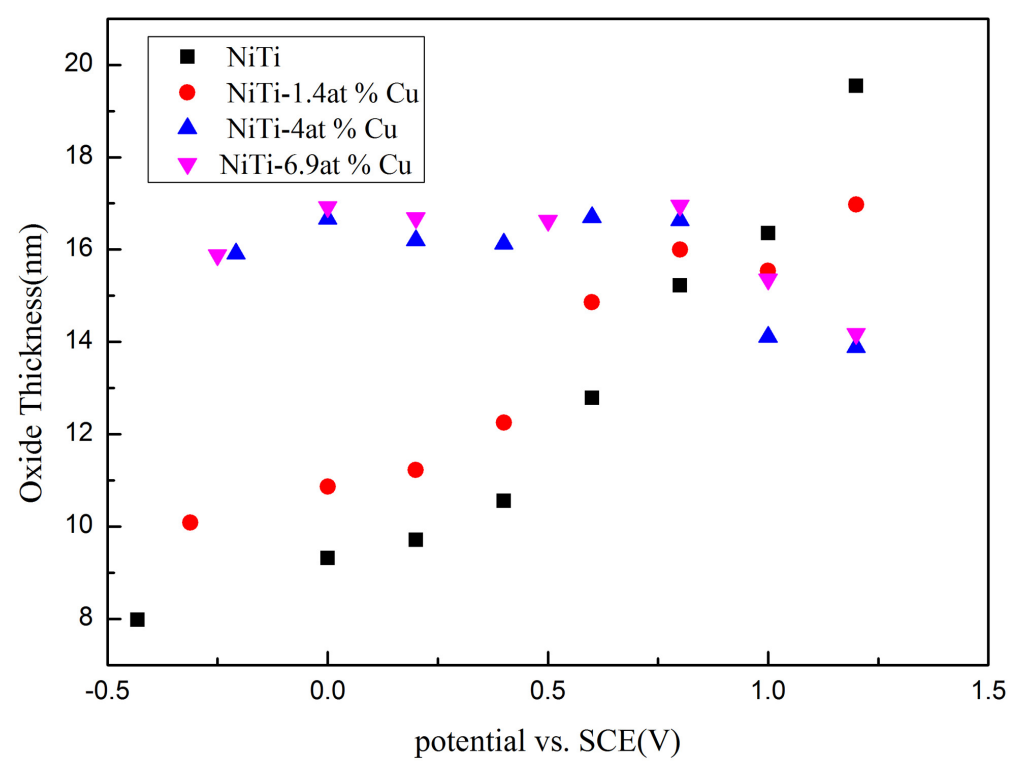

Figure 5. Dependence of oxide thickness on potential for four films in PBS solution.

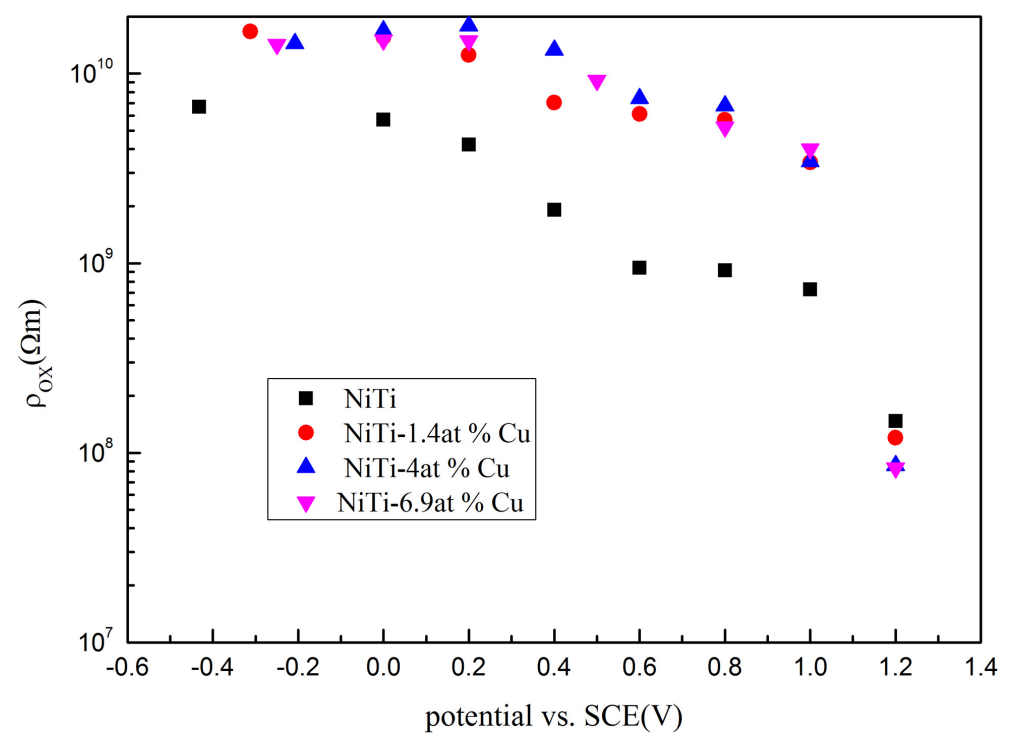

Figure 6. Dependence of oxide resistivity on potential for four films in PBS solution.

layer [16].

Figure 6 shows the change in the oxide resistivity of four films with potential increment. It shows that the oxide resistivity of the four films decreases with the potential increment. This behavior indicates that the oxide layer is defective as the potential increment [16].

\section{Conclusions}

The corrosion resistance of four different amorphous films $\left(\mathrm{Ni}_{49.6} \mathrm{Ti}_{50.4}\right.$, $\left.\mathrm{Ni}_{48.2} \mathrm{Ti}_{50.4} \mathrm{Cu}_{1.4}, \mathrm{Ni}_{45.6} \mathrm{Ti}_{50.4} \mathrm{Cu}_{4}, \mathrm{Ni}_{42.7} \mathrm{Ti}_{50.4} \mathrm{Cu}_{6.9}\right)$ in PBS solution was studied using 
EIS method. The following conclusions were obtained:

1) The corrosion resistance of $\mathrm{Ni}_{49.6} \mathrm{Ti}_{50.4}$ film is superior to that of the other three NiTiCu films in PBS solution at $37^{\circ} \mathrm{C}$. The $\mathrm{Ni}_{48.2} \mathrm{Ti}_{50.4} \mathrm{Cu}_{1.4}$ film had better corrosion resistance than the other two NiTiCu films.

2) The EIS data could be fitted by a parallel resistance-capacitance circuit to obtain the thickness of the oxide layer of the film. The thickness of the oxide layer of $\mathrm{Ni}_{49.6} \mathrm{Ti}_{50.4}$ film is smaller than that of the other three films, but the thickness of the oxide layer of the $\mathrm{Ni}_{49.6} \mathrm{Ti}_{50.4}$ film increased as the potential increment, reaching a maximum at $1.2 \mathrm{~V}$. The thickness of the oxide layer of the other three $\mathrm{NiTiCu}$ films reached a maximum at $0.8 \mathrm{~V}$.

3) The resistivity of the four films was obtained as well. As the potential increased, the resistivity of the four films decreased, indicating that the oxide layer was defective.

\section{Acknowledgements}

National Key R\&D Program of China: Stability Improvement and Product Upgrade of Super Martensitic Stainless Steel Used in Oil and Gas Development: 2016 YFB0300204.

\section{Conflicts of Interest}

The authors declare no conflicts of interest regarding the publication of this paper.

\section{References}

[1] Guo, X., Liu, L., Liu, Y., et al. (2014) Constitutive Model for a Stress- and Thermal-Induced Phase Transition in a Shape Memory Polymer. Smart Materials \& Structures, 23, Article ID: 105019. https://doi.org/10.1088/0964-1726/23/10/105019

[2] Fu, Y., Du, H., Huang, W., et al. (2004) TiNi-Based Thin Films in MEMS Applications: A Review. Sensors \& Actuators A Physical, 112, 395-408. https://doi.org/10.1016/j.sna.2004.02.019

[3] Miyazaki, S., Fu, Y.Q. and Huang, W.M. (2009) Thin Film Shape Memory Alloys: Fundamentals and Device Applications. https://doi.org/10.1017/CBO9780511635366

[4] Fu, Y.Q., Sanjabi, S., Barber, Z.H., et al. (2006) Evolution of Surface Morphology in TiNiCu Shape Memory Thin Films. Applied Physics Letters, 89, 206. https://doi.org/10.1063/1.2361275

[5] Huang, X. (2004) Substrate-Induced Stress and Transformation Characteristics of a Deposited Ti-Ni-Cu Thin Film. Philosophical Magazine, 84, 1919-1936. https://doi.org/10.1080/14786430410004500

[6] Otsuka, K. and Ren, X. (2005) Physical Metallurgy of Ti-Ni-Based Shape Memory Alloys. Progress in Materials Science, 50, 511-678. https://doi.org/10.1016/j.pmatsci.2004.10.001

[7] Duerig, T., Pelton, A. and Stöckel, D. (1999) An Overview of Nitinol Medical Applications. Materials Science \& Engineering A, 273-275, 149-160. https://doi.org/10.1016/S0921-5093(99)00294-4 
[8] Shabalovskaya, S.A. (2002) Surface, Corrosion and Biocompatibility Aspects of Nitinol as an Implant Material. Bio-Medical Materials and Engineering, 12, 69.

[9] Plant, S.D. and Grant, D.L. (2005) Behaviour of Human Endothelial Cells on Surface Modified NiTi Alloy. Biomaterials, 26, 5359-5367.

https://doi.org/10.1016/j.biomaterials.2005.01.067

[10] Gil, F.J., Solano, E., Pena, J., et al. (2004) Microstructural, Mechanical and Citotoxicity Evaluation of Different NiTi and NiTiCu Shape Memory Alloys. Journal of Materials Science Materials in Medicine, 15, 1181-1185. https://doi.org/10.1007/s10856-004-5953-8

[11] Gil, F.J., Solano, E., Mendoza, A., et al. (2004) Inhibition of Ni Release from NiTi and NiTiCu Orthodontic Archwires by Nitrogen Diffusion Treatment. Journal of Applied Biomaterials \& Biomechanics, 2, 151-155.

[12] Bricknell, R.H., Melton, K.N. and Mercier, O. (1979) The Structure of NiTiCu Shape Memory Alloys. Metallurgical Transactions A, 10, 693-697. https://doi.org/10.1007/BF02658390

[13] Rondelli, G. and Vicentini, B. (2002) Effect of Copper on the Localized Corrosion Resistance of Ni-Ti Shape Memory Alloy. Biomaterials, 23, 639-644. https://doi.org/10.1016/S0142-9612(01)00142-9

[14] Liang, C. and Sui, H. (2001) Corrosion Resistance of TiNiCu Shape Memory Alloy. Rare Metal Materials \& Engineering, 30, 93-96.

[15] Es-Souni, M., Es-Souni, M. and Brandies, H.F. (2001) On the Transformation Behaviour, Mechanical Properties and Biocompatibility of Two NiTi-Based Shape Memory Alloys: $\mathrm{NiTi}_{42}$ and $\mathrm{NiTi}_{42} \mathrm{Cu}_{7}$. Biomaterials, 22, 2153-2161. https://doi.org/10.1016/S0142-9612(00)00406-3

[16] Pound, B.G. (2010) The Electrochemical Behavior of Nitinol in Simulated Physiological Solutions. Journal of Biomedical Materials Research Part A, 85, 1103-1113. https://doi.org/10.1002/jbm.a.31616

[17] Pound, B.G. (2010) Electrochemical Behavior of Cobalt-Chromium Alloys in a Simulated Physiological Solution. Journal of Biomedical Materials Research Part A, 94, 93-102. https://doi.org/10.1002/jbm.a.32684

[18] Li, K., Huang, X., Zhao, Z.S., et al. (2016) Electrochemical and Corrosion Behaviors of Sputtered TiNi Shape Memory Films. Smart Materials \& Structures, 25, Article ID: 035039. https://doi.org/10.1088/0964-1726/25/3/035039

[19] Popa, M.V., Demetrescu, I., Vasilescu, E., et al. (2004) Corrosion Susceptibility of Implant Materials Ti-5Al-4V and Ti-6Al-4Fe in Artificial Extra-Cellular Fluids. Electrochimica Acta, 49, 2113-2121. https://doi.org/10.1016/j.electacta.2003.12.036 